\title{
New Forms of Electrospun Nanofibers Applied in Cardiovascular Field
}

\author{
Weimin Huang ${ }^{1,2}$, Mengen $\mathrm{Huo}^{3}$, Nan Cheng ${ }^{2}$ and Rong Wang ${ }^{2 \star}$ \\ ${ }^{1}$ Baotou Clinical Medical College, Inner Mongolia Medical University, Hohhot, China, ${ }^{2}$ Department of Cardiac Surgery, \\ Chinese PLA General Hospital, Beijing, China, ${ }^{3}$ Institute of Poisons and Drugs, Beijing Academy of Military Medical Sciences, \\ Beijing, China
}

\section{OPEN ACCESS}

Edited by:

James J. H. Chong,

The University of Sydney, Australia

Reviewed by:

Michele Miragoli,

University of Parma, Italy

*Correspondence:

Rong Wang

wangrongd@126.com

Specialty section:

This article was submitted to

Cardiovascular Biologics and

Regenerative Medicine,

a section of the journal

Frontiers in Cardiovascular Medicine

Received: 24 October 2021 Accepted: 29 December 2021 Published: 21 January 2022

Citation:

Huang W, Huo M, Cheng N and Wang $R$ (2022) New Forms of

Electrospun Nanofibers Applied in Cardiovascular Field.

Front. Cardiovasc. Med. 8:801077.

doi: 10.3389/fcvm.2021.801077
Cardiovascular disease (CVD) is one of the leading causes of death worldwide. In recent years, regenerative medicine, tissue engineering and the development of new materials have become the focus of attention this field, and electrospinning technology to prepare nanofibrous materials for the treatment of cardiovascular diseases has attracted people's attention. Unlike previous reviews, this research enumerates the experimental methods and applications of electrospinning technology combined with nanofibrous materials in the directions of myocardial infarction repair, artificial heart valves, artificial blood vessels and cardiovascular patches from the perspective of cardiovascular surgery. In the end, this review also summarizes the limitations, unresolved technical challenges, and possible future directions of this technology for cardiovascular disease applications.

Keywords: electrospinning (ES), nanofibers (NFs), cardiac patch, vascular transplantation, tissue engineering

\section{INTRODUCTION}

In 1985, Weinstein and Stason (1) have reported that coronary heart disease (CHD) is the leading cause of death and disability in the United States. One in five Americans develops CHD on their sixtieth birthday. Of these, $11 \%$ did die suddenly and another $44 \%$ suffered a non-fatal myocardial infarction, with an economic burden of well-over $\$ 100$ billion.

In today's society, cardiovascular disease is still the leading cause of death throughout the world, causing more than 17.9 million deaths each year (2). According to the American Heart Association (AHA) estimates, by $2035,46.1 \%$ of the US population will have some form of cardiovascular disease, when the total cost associated with cardiovascular disease will be 1.1 trillion dollars (3), which is enough to see the great harm and burden of cardiovascular disease to humans.

Myocardial infarction is usually due to the lack of oxygen and nutrients in the myocardium, resulting in the death of cardiomyocytes (4). The myocardial tissue after infarction lacks the ability of regeneration. Implanting tissue-engineered myocardium into diseased heart seems to be the simplest way to repair infarcted myocardium. At present, the limitations of myocardial tissue regeneration include the inability to fully summarize the structure and mechanical environment of natural heart tissue (5). Scaffolds made of electrospinning nanofibers have been actively explored for myocardial tissue regeneration.

As shown in the Figure 1, in order to improve the survival rate of stem cells in repairing myocardial injury, electrospinning scaffolds are used to mechanically support and mimic extracellular matrix structure to improve cell adhesion, viability, and regeneration (6). 

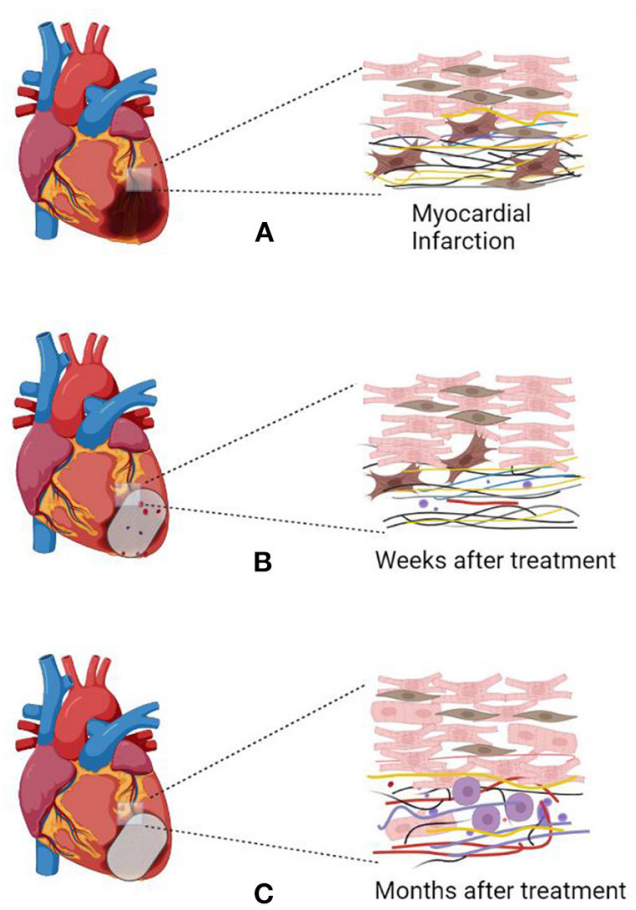

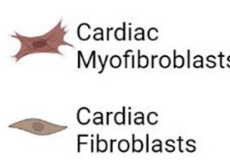

$\because$ Drugs or Fibroblasts

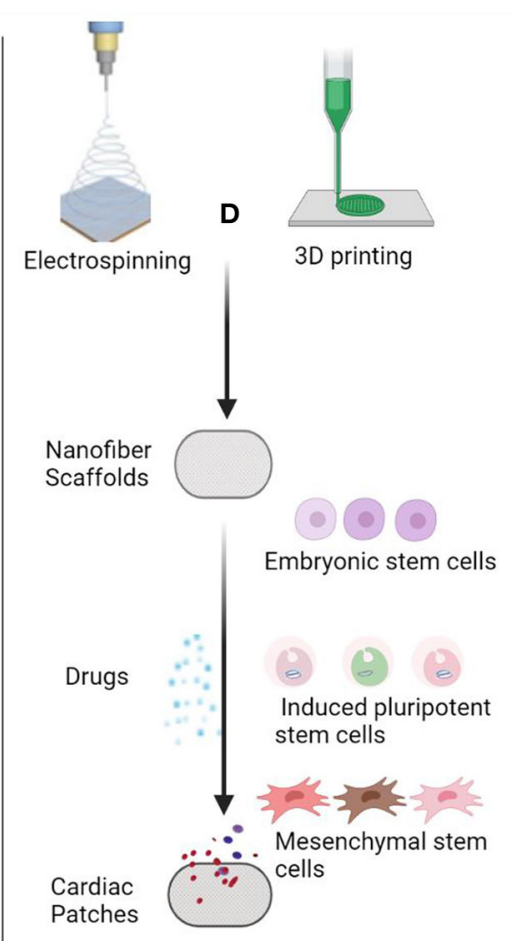

FIGURE 1 | Schematic diagram of cardiac patch repairing myocardial infarction. (A) When myocardial infarction occurs, collagen fibers proliferate and form scar tissue. (B) Several weeks after treatment. (C) Several months after treatment. (D) Cardiac patch is made by electrospinning combined with 3D printing technology. The patch simulates extracellular matrix (ECM) to provide mechanical support for cells. Created with BioRender.com.

More than $50 \%$ of all deaths caused by CVD are attributed to vascular injury induced by vascular plaque aggregation, which leads to vascular obstruction and sclerosis (7). People have been trying to develop appropriate alternative vessels from autologous vascular transplantation, allografts and synthetic grafts. However, these sources could not meet the needs of alternative vessels, especially the long-term patency rate of small-diameter vascular transplantation has always been a difficult problem in the world (8).

For more than 50 years, conventional coronary artery bypass grafting (CABG) has been the gold standard for the treatment of coronary heart disease (9). There are hundreds of thousands of coronary artery bypass procedures in the world each year, for small diameter grafts $(<6 \mathrm{~mm})$, these synthetic grafts often failed due to rapid occlusion and thrombosis, so there is still no effective alternative to autologous vascular grafting $(10,11)$.

The patency and biocompatibility of small-diameter vascular grafts synthesized by traditional tissue engineering strategies are poor (32), and their clinical transformation is seriously limited by high cost and long production time (20). In recent years, tissue engineering using rapidly degradable materials can induce the regeneration potential of the host, and summarize natural tissue regeneration through reasonable graft design, including structural optimization $(30,33)$ and functionalization $(5,34)$.

It is not only required that the small-diameter vascular stent should have the characteristics of maintaining the blood flow in the lumen without leakage, but also that it should have anticoagulant and antithrombotic ability in function to prevent stenosis and occlusion (35). Therefore, many researchers are engaged in electrospinning technology to prepare grafts with different materials, and study the methods to promote the proliferation of vascular intimal endothelial cells and control the proliferation of smooth muscle cells (SMCs). The general method is to fold the electrospinning membrane into a tubular structure through a rolling rod collector, and load heparin (22), growth factors (36) and other active substances (37) on its surface for the study of vascular tissue regeneration. As shown in the Table 1, Animal models, included rat abdominal aorta $(19,20,29)$, rabbit carotid artery $(21-23,29)$, sheep carotid artery (31) and canine femoral artery (38), are often used to test the performance of vascular stents, ranging from several weeks to months. 
TABLE 1 | Construction strategies and vivo/vitro experiments of electrospun fiber membrane in the reviews.

\begin{tabular}{|c|c|c|c|c|c|c|c|}
\hline Nanofiber materials & Diameter/Aperture & Thickness $(\mu \mathrm{m})$ & Drugs or cells & Animals & Experiments & $\begin{array}{l}\text { Time } \\
\text { (weeks) }\end{array}$ & References \\
\hline PCL & $\begin{array}{l}\text { Inner: } 300 \pm 100 \mathrm{~nm} \\
\text { Out: } 2.8 \pm 0.13 \mu \mathrm{m}\end{array}$ & $100 \mu \mathrm{m}$ & Cardiomyocytes /fibroblasts & Mice & In vitro & 1 & (12) \\
\hline PLGA & N/A & $110 \pm 10 \mu \mathrm{m}$ & $\begin{array}{l}\text { Endothelial cells, VEGF } \\
\text { granules, dexamethasone }\end{array}$ & Mice & Cardiac patch & 2 & (13) \\
\hline PCL-Gelatin & $578 \pm 184 \mathrm{~nm}$ & $115 \pm 11 \mu \mathrm{m}$ & hiPSC-CMs & N/A & In vitro & 2 & (6) \\
\hline$\beta-P V D F$ & N/A & N/A & $\mathrm{TiO} 2$ & N/A & In vitro & $6^{*}$ & (15) \\
\hline AuNRs & $500 \mathrm{~nm} / 20-60 \mathrm{~nm}$ & $60-80 / 100-120 \mu \mathrm{m}$ & $\begin{array}{l}\text { Left ventricular } \\
\text { cardiomyocytes }\end{array}$ & Mice & Cardiac patch (Near IR) & 1 & (16) \\
\hline $\begin{array}{l}\text { PCL/GelMA-Ppy } \\
\text { nanoparticles }\end{array}$ & $948 \pm 153 \mathrm{~nm}$ & N/A & Cardiomyocytes/fibroblasts & Mice & $\begin{array}{l}\text { Cardiac patch } 1.5 \times \\
1.5 \mathrm{~cm}\end{array}$ & 4 & (17) \\
\hline $\begin{array}{l}\text { PELCL/chitosan- } \\
\text { hydrogel }\end{array}$ & $\begin{array}{l}\text { Inner: } 754 \pm 385 \mathrm{~nm} \\
\text { Out: } 1,087 \pm 526 \mathrm{~nm}\end{array}$ & $\mathrm{~N} / \mathrm{A}$ & $\begin{array}{l}\text { Inner: VEGF } \\
\text { Out: PDGF }\end{array}$ & Rabbits & $\begin{array}{l}\text { Carotid artery } \\
\text { transplantation }\end{array}$ & 4 & (21) \\
\hline PLCL & $821 \pm 102.87 \mathrm{~nm}$ & $300 \pm 17 \mu \mathrm{m}$ & Heparin / Silk Fibroin & Rabbits & $\begin{array}{l}\text { Carotid artery } \\
\text { transplantation }\end{array}$ & 32 & (22) \\
\hline PCL & $263.1 \pm 90.2 \mathrm{~nm}$ & $\mathrm{~N} / \mathrm{A}$ & KSNO & Rabbits & $\begin{array}{l}\text { Carotid artery } \\
\text { transplantation }\end{array}$ & 4 & (23) \\
\hline PLA-PCL & N/A & $40 \pm 7 / 175 \pm 4 \mu \mathrm{m}$ & Human fibroblast & N/A & In vitro & 8 & (24) \\
\hline ADF4(C16) & $1.6 \pm 0.2 \mu \mathrm{m}$ & N/A & N/A & Mice & $\begin{array}{l}\text { Arteriovenous loop } \\
\text { model }\end{array}$ & 4 & (25) \\
\hline ESM/TPU & $435.86 \pm 173.27 \mathrm{~nm}$ & $50-70 \mu \mathrm{m}$ & HUVEC & N/A & In vitro & 1 & (26) \\
\hline CS-PVA-CNT & $255 \pm 3.5 \mathrm{~nm}$ & $\mathrm{~N} / \mathrm{A}$ & MSCs & N/A & In vitro & 3 & (11) \\
\hline PCL/collagen scaffolds & $4.45 \pm 0.81 \mu \mathrm{m}$ & $400 \mu \mathrm{m}$ & ECs/SMCs & Sheep & $\begin{array}{l}\text { Carotid artery, } 4.75 \mathrm{~mm} \\
\times 5 \mathrm{~cm}\end{array}$ & 24 & (31) \\
\hline $\begin{array}{l}\text { PELCL/chitosan } \\
\text { hydrogel }\end{array}$ & $\begin{array}{l}754 \pm 385 \mathrm{~nm} \\
1,124 \pm 529 \mathrm{~nm}\end{array}$ & $\mathrm{~N} / \mathrm{A}$ & VEGF/PDGF & Rabbits & Carotid artery, $2.2 \mathrm{~mm}$ & 4 & (21) \\
\hline
\end{tabular}

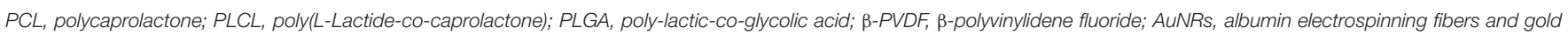

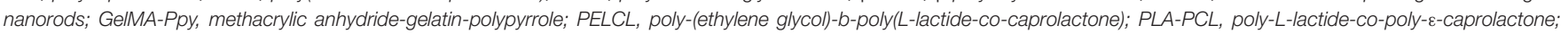

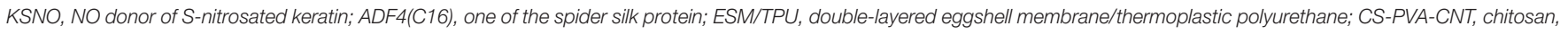

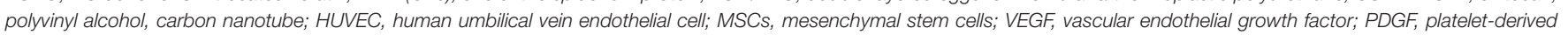
growth factor; ECs, endothelial cells; SMCs, smooth cells.

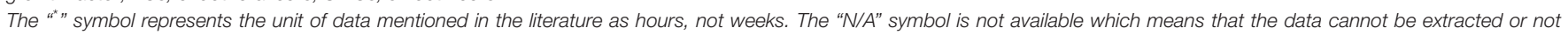
mentioned in this article.

With the development of tissue engineering technologies in recent years, a series of nanofibrous materials based on electrospinning technology have attracted much attention of researchers (39).

In the field of cardiovascular tissue regeneration, compared with traditional regeneration technology, electrospinning technology has the following advantages:
1. The cardiac patches loaded with stem cells can repair the infarcted myocardial region without limiting the later cardiac systolic activity.

2. Simulating the unique physical structure of natural cardiac leaflets, the leaflet structure with the same anisotropy and mechanical strength is provided. 
3. The vascular scaffold can be used to match the proliferation of vascular endothelial cells with the degradation of the material, so as to ensure a higher patency rate.

4. It can provide intelligent health monitoring function, which can early evaluate and prevent acute and chronic cardiovascular diseases.

In this study, we would focus on nanofibers, introduce the progress of different electrospinning technologies in the field of heart and vessel-related tissue engineering, compare the effect of some nanofiber materials, and forecast the development of electrospinning technology in the field of cardiovascular medicine and the problems to be broken through.

\section{Myocardial Infarction Repair}

From the microstructure,Sharon Fleischer (12) divided the myocardium into three fiber groups with specific effect and different sizes: nanoscale endomysial fibers, perimysial fibers with a diameter of $1 \mu \mathrm{m}$ and epimysium fibers with a diameter of several microns. He also reported that the electrospinning fiber stent with spring-like coiled fiber structure was conducive to cardiac tissue engineering. Later, the team (13) designed a cage structure with microgrooves and sidewall microchannel albumin stent to arrange the cardiac tissue and accommodate the growth of endothelial cells. This cage structure can also accommodate the particle system, control the release of VEGF, promote vascularization, and even load dexamethasone drugs to achieve the effect. In addition, Zhu et al. (18) mixed the polymer caprolactone with caprolactone $\mathrm{NO}_{2}$ to prepare nitric acid-functionalized cardiac patches to implant the site of myocardial infarction using the electrospinning method. The results showed that NO was gradually released from the patch under ischemic microenvironment, and the effect of NO patch group was significant. What attracts our attention is an aligned polycaprolactone (PCL) -Gelatin coaxial nanofiber patch was fabricated by Kuma (6) using electrospinning. The results show that cells on cardiac patches exhibit synchronous contraction and exhibit a rapid response to cardiac drugs. The patches could be scaled to serve as an in vitro drug screening platform for cardiotoxicity studies.

Despite some success with cell-loading techniques, many scaffolds have limited cell infiltration and low cell survival (40). In order to overcome the limited cell infiltration of cardiac patches and also consider the supporting mechanical properties of these patches, Chen and Kan (14) designed the thickness of the patches to about $50 \mu \mathrm{m}$. Both bone marrow and human cardiac stem cells cultured on these patches had good survival and infiltration $(\sim 30 \mu \mathrm{m})$. In addition, the tensile strength of the patch could withstand the severe pumping effect of myocardium, confirming that the material prepared by this method has the potential to be used as a scaffold for cardiomyocyte repair and application. Unlike the above ideas, the glycosaminoglycan (GAG) mimetic peptide nanofiber gel synthesized by Rufaihah et al. (41) was injected into the infarct site, emphasizing its approach of repairing the myocardium and inducing neovascularization without adding any biologically derived factors or stem cells. This predicts the possibility of electrospinning technology combined with nanofibrous hydrogels in tissue engineering.

In order to avoid the problem of additional damage caused by suturing the patch to the heart using surgical means in the past, Malki et al. (16) developed a nanocomposite scaffold composed of albumin electrospinning fibers and gold nanorods (AuNRs), which was positioned and irradiated with a nearinfrared laser $(808 \mathrm{~nm})$, and AuNRs were able to absorb light and convert it into thermal energy, locally change the molecular structure of the fibrous scaffold, eventually attach it strongly but safely to the heart wall. Subsequently, $\mathrm{He}$ et al. (17) were inspired by mussels to design conductive nanofibrous membranes to repair myocardial infarction by enhancing cardiac function and revascularization. The result showed that 4 weeks after patch transplantation on the infarcted heart, the infarct size was reduced by about $50 \%$, the percentage of left ventricular fraction was increased by about $20 \%$, and the density of neovascularization in the infarcted area was significantly increased by about 9 -fold compared with the control group.

In order for the patches to exhibit mechanical and conductive properties similar to those of autologous myocardium, Walker et al. (42) developed cardiac gaskets, first of which was gelatin methacryloyl (GelMA), followed by highly adhesive fibrous scaffolds modified with conjugated choline-based biological ionic liquids (bio-IL), based on the formation of ionic bonds between Bio-IL and native tissue, and the engineered patches adhered strongly to rat myocardium without suturing.

In order to establish a model for evaluating the performance of engineered heart in vitro, Polylactic acid (PLA) and poly- $\varepsilon$ caprolactone (PCL) were used to fabricate the porous scaffold via $3 \mathrm{D}$ printing and electrospinning, and then cardiomyocytes from neonatal Sprague Dawley (SD) rats were cultured on the PLA/PCL scaffold to construct the engineered cardiac tissue (ECT). The strength and biocompatibility of the scaffold were verified via evaluating the cell viability and mechanical beating status (43). This work provides a new approach for evaluating ECT, which is expected to be applied to pharmaceutical studies.

\section{Tissue Engineering of Heart Valves}

At present, biological valves also have some limitations, especially in young patients, so it is critical to continue to develop new materials. But heart valve tissue engineering still faces challenges, for example, the valve component has three layers, which are circumferential, random and radial, respectively, which increases the difficulty of material preparation. Wu et al. (44) began to believe that the hydrogel system of methacrylic hyaluronic acid (Me-HA) and methacrylate gelatin (Me-Gel) mixed with each other can simulate the unique $3 \mathrm{D}$ physiological microenvironment of the ECM of native aortic valve leaflets, but it was later found that these hydrogel materials lacked macroscopic anisotropic structure and had weak extension ability, so it was thought to compensate for the disadvantages of hydrogels by adding fibrous components.

In order to better simulate the direction, Jana and Lerman (45) from Mayo Clinic firstly designed three new collectors to fabricate three nanofiber layers with these directions from polymeric biomaterials in electrospinning systems. 


\section{Cardiac Surgeries}

In order to develop a new generation of biomaterials for closure of atrial septal defect, Kaiser firstly designed chamber-deficient patches using medical grade polyurethane loaded with bioactive agents chitosan nanoparticles and collagen, followed by coating with heparin (46). In the postoperative aspect of cardiac surgery, sternal and epicardial adhesions increase the risk and complexity of cardiac reoperation, which is a significant challenge for the later rehabilitation of all patients who underwent cardiac surgery again. Feng et al. (47) fabricated a bioabsorbable GT/PCL composite membrane to prevent adhesions in cardiac surgery in a rabbit model and proposed its use as a novel pericardial substitute for cardiac surgery.

\section{Small-Caliber Vascular Grafts}

At present, there are practical non-tissue engineered grafts for large vessels in clinical practice, but doctors often face failure in front of small-caliber vascular grafts due to the easy thrombosis. To prevent thrombosis, Zhang et al. (21) developed two modified coaxial electrospinning techniques, which are to achieve vascular compliance. Interestingly, previous studies have been observed in vascular transplantation experiments for a maximum of 3 months (19), while Qin et al. (20) reported the time up to 6 months. They agreed that the vascular smooth muscle layer is essential for maintaining the mechanical strength and vasoactive reactivity of blood vessels, so hyaluronic acid was loaded on rapidly biodegradable vascular grafts in the study and concluded that it promotes vascular smooth muscle regeneration.

However, Kuang et al. (22) considered that smooth muscle cells (SMCs) are prone to excessive proliferation and cause restenosis at the late stage of implantation. In order to develop a safe and unobstructed artificial blood vessel, they prepared a small-caliber artificial blood vessel with composite nanofiber nucleocapsid structure by a combination of conjugated electrospinning and lyophilization technology. The inner layer provides mechanical support during vascular reconstruction. The shell, heparin/silk fibroin layer, enhances the biocompatibility of the graft, and the release of heparin at the early stage after transplantation can regulate the microenvironment, promote endothelial cell growth and inhibit smooth muscle proliferation. This animal experiment showed that the graft patency time remained more than 8 months, which far exceeded 3 months which $\mathrm{Wu}$ has reported (19).

In order to better promote the endo-thelialization of transplanted vessels and simulate the extracellular matrix, hyaluronic acid oligosaccharide-modified collagen was fabricated into nanofibers by electrospinning technique in Kang et al. (48) from Shandong University. The in vitro experimental results supported that it promoted endothelial cell proliferation and had antithrombotic properties. Lee et al. (39) of Seoul University encapsulated human ASC spheres in alginate-based scaffolding structures by a combined 3D printing/electrospinning system. In order to treat peripheral arterial occlusive disease, Dorati preliminarily explored the replacement of artificial blood vessels in damaged peripheral arteries, which showed that the electrospinning technique was suitable for obtaining grafts
$<6 \mathrm{~mm}$ in diameter and between $140 \pm 7$ and $175 \pm$ $4 \mu \mathrm{m}$ in thickness. Finally, vascular grafts with the best mechanical properties similar to natural bovine blood vessels were designed (24).

In order to reduce the toxicity of transplanted blood vessels, Li et al. (23) synthesized a low-toxic NO donor of $S$-nitrosated keratin (KSNO) and then co-electrospinning with poly- $\varepsilon$-caprolactone to obtain NO-releasing small-diameter vascular grafts. In order to improve the biocompatibility of transplantation, Yan et al. (26) reported a wavy structure of smalldiameter, double-layered eggshell membrane/thermoplastic polyurethane (ESM/TPU) vascular graft.

It is not easy to maintain good supporting performance of transplanted blood vessels and make their cell adhesion strong. To obtain vascular graft with stronger mechanical properties and cell-guided growth ability, Liu has developed a biomimetic three-layer vascular graft with strong mechanical properties and cell-guided growth ability (30).

Of course, the strategy of vascular tissue engineering is eventually to combine autologous vascular cells with tubular biodegradable scaffolds, and Ju et al. did manufacture vascular substitutes (31). This study demonstrates that electrospinning double-layer vascular scaffolds combined with autologous vascular cells may be a clinically applicable alternative to conventional graft substitutes.

\section{Vascular Patches}

Vascular patches currently used in cardiovascular surgery have several disadvantages, including material degeneration, calcification, and pseudointimal hyperplasia leading to hemodynamic disturbances (28). Initially Chantawong et al. (29) created three patches of different composition using an electrospinning method, all of which were made of a combination of silk fibroin (SF) and a synthetic polymer thermoplastic polyurethane (TPU). They implanted each type of patch $(n=18)$ into the abdominal aorta of rats and assessed histopathology at 1,3, and 6 months after implantation, and concluded that the increase in SF concentration in SF/PU patches had a positive effect on vascular remodeling. Later, Shimada et al. (28) in the team replaced part of the descending aortic wall of the dog with SF/TPU patches for this experiment, and the patches were removed 3 months later for histological examination.

\section{Surgical Induction of Angiogenesis}

Although encouraging results have now been achieved with tissue engineering, the short-term integration of tissue-engineered constructs with the host vasculature remains one of the major obstacles (25). In addition to integrating endothelial cells (49) or angiogenic growth factors (50), surgery-induced angiogenesis appears to be a promising strategy to improve vascularization. In 1980, Erol and Sira (51) demonstrated that neovascularization of the skin through arteriovenous fistula is possible. A vascular bed can be created by use of long inter-positional vein grafts. In 2019, Steiner conducted a similar experiment which resulted that spider silk proteins have good biocompatibility and slow 
biodegradation, thinner electrospinning fibers showed faster biodegradation and vascularization (25).

\section{DISCUSSION}

\section{Limitations and Challenges}

In the past two decades, through electrospinning technology, cell-loaded nanofiber scaffolds have been widely studied in wound healing (52), drug delivery (53), and cardiac patches $(14,15,46,54-56)$ have shown good performance in preclinical studies of cardiac repair, there are still many problems before clinical implementation (57), such as cardiac patch therapy currently requiring open-heart surgery, which causes anxiety in most patients with myocardial infarction (58), low degree of cell infiltration and cell survival on electrospinning scaffolds $(40,59)$, insufficient mechanical support performance (60), and biocompatibility that cannot meet clinical needs (61).

The current nanofiber scaffold technology is plagued by some limitations that must be overcome in order to produce highly functional and treatment-related functional engineered cardiac tissues (fECTs), including: (1) Low porosity hinders the deep penetration of seed cells, (2) When cardiomyocytes are cultured on a rigid substrate mimicking a post-infarct fibrotic scar, they lose their synchronized beating, and (3) It is difficult to expand the technology currently used in human applications $(62,63)$.

In terms of small vessel tissue engineering, Kuang et al. transplanted composite nanofibrous small vessel grafts prepared by a combination of conjugated electrospinning and lyophilization techniques into rabbit carotid arteries (22). Although this team considers matching the degradation rate of vascular stents with the rate of tissue remodeling, it remains a challenge to synchronize the stent degradation rate and new tissue formation rate over a period of time $(64,65)$.

\section{REFERENCES}

1. Weinstein MC, Stason WB. Cost-effectiveness of interventions to prevent or treat coronary heart disease. Annu Rev Public Health. (1985) 6:4163. doi: 10.1146/annurev.pu.06.050185.000353

2. Roth GA, Johnson C, Abajobir A, Abd-Allah F, Abera SF, Abyu G, et al. Global, regional, and national burden of cardiovascular diseases for 10 causes, 1990 to 2015. J Am Coll Cardiol. (2017) 70:1-25. doi: 10.1016/j.jacc.2017.04.052

3. Benjamin EJ, Virani SS, Callaway CW, Chamberlain AM, Chang AR, Cheng S, et al. Heart disease and stroke statistics-2018 update: a report from the american heart association. Circulation. (2018) 137:e67492. doi: 10.1161/CIR.0000000000000573

4. Lodrini AM, Goumans MJ. Cardiomyocytes cellular phenotypes after myocardial infarction. Front Cardiovasc Med. (2021) 8:750510. doi: 10.3389/fcvm.2021.750510

5. Weinberger F, Mannhardt I, Eschenhagen T. Engineering cardiac muscle tissue: a maturating field of research. Circ Res. (2017) 120:1487-500. doi: 10.1161/CIRCRESAHA.117.310738

6. Kumar N, Sridharan D, Palaniappan A, Dougherty JA, Czirok A, Isai DG, et al. Scalable biomimetic coaxial aligned nanofiber cardiac patch: a potential model for "clinical trials in a dish". Front Bioeng Biotechnol. (2020) 8:567842. doi: $10.3389 /$ fbioe. 2020.567842

\section{Potential Development Direction of Electrospinning}

The primary goal of electrospinning technology in cardiovascular tissue regeneration is to prepare good biomimetic scaffolds in vitro to regenerate myocardium or vascular tissue and restore their function, and then study their biocompatibility and specific function in vivo tests $(11,27)$.

We may try to do the combination of electrospinning with nanofiber hydrogels (66) to improve their mechanical properties. We can also continue to develop more 3D printed scaffolds as templates to promote cardiomyocyte infiltration (67).

The continuously updated electrospinning technology will certainly promote the development of cardiovascular tissue engineering, such as the melt electrospinning fabricated sinusoidal fibers showing great potential in cardiac tissue regeneration $(68,69)$.

\section{AUTHOR CONTRIBUTIONS}

WH wrote the text of this review paper with guidance from RW. NC and MH made valuable suggestions. All authors have reviewed the final version and approved of the content in this manuscript.

\section{FUNDING}

This work was supported by grants from Military Medicine Youth Special Project of Chinese PLA General Hospital (20QNPY096).

\section{ACKNOWLEDGMENTS}

All authors hereby thank Professor Yunze Long and his student Yuan Gao from Qingdao University for their constructive suggestions and great help in this paper.

7. Gui L, Dash BC, Luo J, Qin L, Zhao L, Yamamoto K, et al. Implantable tissue-engineered blood vessels from human induced pluripotent stem cells. Biomaterials. (2016) 102:120-9. doi: 10.1016/j.biomaterials.2016.06.010

8. Navarro RS, Jiang L, Ouyang Y, Luo J, Liu Z, Yang Y, et al. Biomimetic tubular scaffold with heparin conjugation for rapid degradation in in situ regeneration of a small diameter neoartery. Biomaterials. (2021) 274:120874. doi: 10.1016/j.biomaterials.2021.120874

9. Alasnag $\mathrm{M}$, Yaqoub L, Saati A, Al-Shaibi K. Left main coronary artery interventions. Interv Cardiol. (2019) 14:124-30. doi: 10.15420/icr.2019.10.R2

10. Tara S, Kurobe H, Maxfield MW, Rocco KA, Yi T, Naito Y, et al. Evaluation of remodeling process in small-diameter cell-free tissue-engineered arterial graft. J Vasc Surg. (2015) 62:734-43. doi: 10.1016/j.jvs.2014.03.011

11. Mombini S, Mohammadnejad J, Bakhshandeh B, Narmani A, Nourmohammadi J, Vahdat S, et al. Chitosan-PVA-CNT nanofibers as electrically conductive scaffolds for cardiovascular tissue engineering. Int $J$ Biol Macromol. (2019) 140:278-87. doi: 10.1016/j.ijbiomac.2019.08.046

12. Fleischer S, Miller J, Hurowitz H, Shapira A, Dvir T. Effect of fiber diameter on the assembly of functional 3D cardiac patches. Nanotechnology. (2015) 26:291002. doi: 10.1088/0957-4484/26/29/291002

13. Fleischer S, Shapira A, Feiner R, Dvir T. Modular assembly of thick multifunctional cardiac patches. Proc Natl Acad Sci U S A. (2017) 114:1898903. doi: 10.1073/pnas.1615728114 
14. Chen WL, Kan CD. Using cell-seeded electrospun patch for myocardial injury: in-vitro and in rat model. Annu Int Conf IEEE Eng Med Biol Soc. (2018) 2018:5338-41. doi: 10.1109/EMBC.2018.8513557

15. Arumugam R, Srinadhu ES, Subramanian B, Nallani S. $\beta$-PVDF based electrospun nanofibers - a promising material for developing cardiac patches. Med Hypotheses. (2019) 122:31-4. doi: 10.1016/j.mehy.2018.10.005

16. Malki M, Fleischer S, Shapira A, Dvir T. Gold nanorod-based engineered cardiac patch for suture-free engraftment by near IR. Nano Letters. (2018) 18:4069-73. doi: 10.1021/acs.nanolett.7b04924

17. He Y, Ye G, Song C, Li C, Xiong W, Yu L, et al. Mussel-inspired conductive nanofibrous membranes repair myocardial infarction by enhancing cardiac function and revascularization. Theranostics. (2018) 8:5159-77. doi: 10.7150/thno.27760

18. Zhu D, Hou J, Qian M, Jin D, Hao T, Pan Y, et al. Nitratefunctionalized patch confers cardioprotection and improves heart repair after myocardial infarction via local nitric oxide delivery. Nat Commun. (2021) 12:4501. doi: 10.1038/s41467-021-24804-3

19. Wu W, Allen RA, Wang Y. Fast-degrading elastomer enables rapid remodeling of a cell-free synthetic graft into a neoartery. Nat Med. (2012) 18:1148-53. doi: 10.1038/nm.2821

20. Qin K, Wang F, Simpson RML, Zheng X, Wang H, Hu Y, et al. Hyaluronan promotes the regeneration of vascular smooth muscle with potent contractile function in rapidly biodegradable vascular grafts. Biomaterials. (2020) 257:120226. doi: 10.1016/j.biomaterials.2020.120226

21. Zhang H, Jia X, Han F, Zhao J, Zhao Y, Fan Y, et al. Dual-delivery of VEGF and PDGF by double-layered electrospun membranes for blood vessel regeneration. Biomaterials. (2013) 34:2202-12. doi: 10.1016/j.biomaterials.2012. 12.005

22. Kuang H, Wang Y, Shi Y, Yao W, He X, Liu X, et al. Construction and performance evaluation of Hep/silk-PLCL composite nanofiber small-caliber artificial blood vessel graft. Biomaterials. (2020) 259:120288. doi: 10.1016/j.biomaterials.2020.120288

23. Li P, Jin D, Dou J, Wang L, Wang Y, Jin X, et al. Nitric oxidereleasing poly( $\varepsilon$-caprolactone) /S-nitrosylated keratin biocomposite scaffolds for potential small-diameter vascular grafts. Int J Biol Macromol. (2021) 189:516-27. doi: 10.1016/j.ijbiomac.2021.08.147

24. Dorati R, Pisani S, Chiesa E, Genta I, Bruni G, Modena T, et al. Electrospun tubular vascular grafts to replace damaged peripheral arteries: a preliminary formulation study. Int J Pharm. (2021) 596:120198. doi: 10.1016/j.ijpharm.2021.120198

25. Steiner D, Lang G, Fischer L, Winkler S, Fey T, Greil P, et al. Intrinsic vascularization of recombinant eadf4(c16) spider silk matrices in the arteriovenous loop model. Tissue Eng Part A. (2019) 25:150413. doi: 10.1089/ten.tea.2018.0360

26. Yan S, Napiwocki B, Xu Y, Zhang J, Zhang X, Wang X, et al. Wavy small-diameter vascular graft made of eggshell membrane and thermoplastic polyurethane. Mater Sci Eng C Mater Biol Appl. (2020) 107:110311. doi: 10.1016/j.msec.2019.110311

27. Du H, Tao L, Wang W, Liu D, Zhang Q, Sun P, et al. Enhanced biocompatibility of poly(llactidecoepsiloncaprolactone) electrospun vascular grafts via self-assembly modification. Mater Sci Eng C Mater Biol Appl. (2019) 100:845-54. doi: 10.1016/j.msec.2019.03.063

28. Shimada R, Konishi H, Ozawa H, Katsumata T, Tanaka R, Nakazawa Y, et al. Development of a new surgical sheet containing both silk fibroin and thermoplastic polyurethane for cardiovascular surgery. Surg Today. (2018) 48:486-94. doi: 10.1007/s00595-017-1615-6

29. Chantawong P, Tanaka T, Uemura A, Shimada K, Higuchi A, Tajiri H, et al. Silk fibroin-Pellethane $($ cardiovascular patches: Effect of silk fibroin concentration on vascular remodeling in rat model. J Mater Sci Mater Med. (2017) 28:191. doi: 10.1007/s10856-017-5999-z

30. Liu K, Wang N, Wang W, Shi L, Li H, Guo F, et al. A bio-inspired high strength three-layer nanofiber vascular graft with structure guided cell growth. J Mater Chem B. (2017) 5:3758-64. doi: 10.1039/C7TB00465F

31. Ju YM, Ahn H, Arenas-Herrera J, Kim C, Abolbashari M, Atala A, et al. Electrospun vascular scaffold for cellularized small diameter blood vessels: a preclinical large animal study. Acta Biomater. (2017) 59:5867. doi: 10.1016/j.actbio.2017.06.027
32. Wang Z, Mithieux SM, Weiss AS. Fabrication techniques for vascular and vascularized tissue engineering. $A d v$ Healthc Mater. (2019) 8:e1900742. doi: 10.1002/adhm.2019 00742

33. Wang Z, Cui Y, Wang J, Yang X, Wu Y, Wang K, et al. The effect of thick fibers and large pores of electrospun poly(epsilon-caprolactone) vascular grafts on macrophage polarization and arterial regeneration. Biomaterials. (2014) 35:5700-10. doi: 10.1016/j.biomaterials.2014.03.078

34. Issa Bhaloo $\mathrm{S}$, $\mathrm{Wu} \mathrm{Y}$, Le Bras $\mathrm{A}, \mathrm{Yu} \mathrm{B}, \mathrm{Gu} \mathrm{W}$, Xie $\mathrm{Y}$, et al Binding of dickkopf-3 to CXCR7 enhances vascular progenitor cell migration and degradable graft regeneration. Circ Res. (2018) 123:45166. doi: 10.1161/CIRCRESAHA.118.312945

35. Badv M, Bayat F, Weitz JI, Didar TF. Single and multi-functional coating strategies for enhancing the biocompatibility and tissue integration of blood-contacting medical implants. Biomaterials. (2020) 258:120291. doi: 10.1016/j.biomaterials.2020.120291

36. Han F, Jia X, Dai D, Yang X, Zhao J, Zhao Y, et al. Performance of a multilayered small-diameter vascular scaffold dualloaded with VEGF and PDGF. Biomaterials. (2013) 34:730213. doi: 10.1016/j.biomaterials.2013.06.006

37. Strobel HA, Qendro EI, Alsberg E, Rolle MW. Targeted delivery of bioactive molecules for vascular intervention and tissue engineering. Front Pharmacol. (2018) 9:1329. doi: 10.3389/fphar.2018.01329

38. Xue J, Wu T, Dai Y, Xia Y. Electrospinning and electrospun nanofibers: methods, materials, and applications. Chem Rev. (2019) 119:5298-415. doi: 10.1021/acs.chemrev.8b00593

39. Lee JS, Chae S, Yoon D, Yoon D, Chun W, Kim GH. Angiogenic factors secreted from human ASC spheroids entrapped in an alginate-based hierarchical structure via combined 3D printing/electrospinning system. Biofabrication. (2020) 12:045028. doi: 10.1088/1758-5090/abaf9a

40. Lin W, Chen M, Qu T, Li J, Man Y. Three-dimensional electrospun nanofibrous scaffolds for bone tissue engineering. J Biomed Mater Res Part B Appl Biomater. (2020) 108:1311-21. doi: 10.1002/jbm.b.34479

41. Rufaihah AJ, Yasa IC, Ramanujam VS, Arularasu SC, Kofidis T, Guler MO, et al. Angiogenic peptide nanofibers repair cardiac tissue defect after myocardial infarction. Acta Biomater. (2017) 58:102-12. doi: 10.1016/j.actbio.2017.06.009

42. Walker BW, Lara RP, Yu CH, Sani ES, Kimball W, Joyce S, et al. Engineering a naturally-derived adhesive and conductive cardiopatch. Biomaterials. (2019) 207:89-101. doi: 10.1016/j.biomaterials.2019.03.015

43. Wei X, Gao Q, Xie C, Gu C, Liang T, Wan H, et al. Extracellular recordings of bionic engineered cardiac tissue based on a porous scaffold and microelectrode arrays. Analytical Methods. (2019) 11:58729. doi: 10.1039/C9AY01888C

44. Wu S, Duan B, Qin X, Butcher JT. Living nano-micro fibrous woven fabric/hydrogel composite scaffolds for heart valve engineering. Acta Biomater. (2017) 51:89-100. doi: 10.1016/j.actbio.2017.01.051

45. Jana S, Lerman A. Behavior of valvular interstitial cells on trilayered nanofibrous substrate mimicking morphologies of heart valve leaflet. Acta Biomater. (2019) 85:142-56. doi: 10.1016/j.actbio.2018.12.005

46. Kaiser E, Jaganathan SK, Supriyanto E, Ayyar M. Fabrication and characterization of chitosan nanoparticles and collagen-loaded polyurethane nanocomposite membrane coated with heparin for atrial septal defect (ASD) closure. 3 Biotech. (2017) 7:174. doi: 10.1007/s13205-017-0830-6

47. Feng B, Wang S, Hu D, Fu W, Wu J, Hong $\mathrm{H}$, et al. Bioresorbable electrospun gelatin/polycaprolactone nanofibrous membrane as a barrier to prevent cardiac postoperative adhesion. Acta Biomater. (2019) 83:21120. doi: 10.1016/j.actbio.2018.10.022

48. Kang L, Jia W, Li M, Wang Q, Wang C, Liu Y, et al. Hyaluronic acid oligosaccharide-modified collagen nanofibers as vascular tissue-engineered scaffold for promoting endothelial cell proliferation. Carbohydr Polym. (2019) 223:115106. doi: 10.1016/j.carbpol.2019.115106

49. Strassburg S, Nienhueser H, Bjorn Stark G, Finkenzeller G, Torio-Padron $\mathrm{N}$. Co-culture of adipose-derived stem cells and endothelial cells in fibrin induces angiogenesis and vasculogenesis in a chorioallantoic membrane model. J Tissue Eng Regen Med. (2016) 10:496-506. doi: 10.1002/term .1769

50. Arkudas A, Pryymachuk G, Hoereth T, Beier JP, Polykandriotis E, Bleiziffer O, et al. Dose-finding study of fibrin gel-immobilized vascular endothelial growth 
factor 165 and basic fibroblast growth factor in the arteriovenous loop rat model. Tissue Eng Part A. (2009) 15:2501-11. doi: 10.1089/ten.tea.2008.0477

51. Erol OO, Sira M. New capillary bed formation with a surgically constructed arteriovenous fistula. Plast Reconstr Surg. (1980) 66:10915. doi: 10.1097/00006534-198007000-00021

52. Pezeshki-Modaress $M$, Mirzadeh H, Zandi M, Rajabi-Zeleti S, Sodeifi N, Aghdami N, et al. Gelatin/chondroitin sulfate nanofibrous scaffolds for stimulation of wound healing: In-vitro and in-vivo study. J Biomed Mater Res A. (2017) 105:2020-34. doi: 10.1002/jbm.a. 35890

53. Chen S, Li R, Li X, Xie J. Electrospinning: an enabling nanotechnology platform for drug delivery and regenerative medicine. Adv Drug Deliv Rev. (2018) 132:188-213. doi: 10.1016/j.addr.2018.05.001

54. Rolph D, Das H. Generation of Myocardial Ischemic Wounds and Healing with Stem Cells. Methods Mol Biol. (2021) 2193:1417. doi: 10.1007/978-1-0716-0845-6_14

55. Sharma D, Ferguson M, Kamp TJ, Zhao F. Constructing biomimetic cardiac tissues: a review of scaffold materials for engineering cardiac patches. Emerg Mater. (2019) 2:181-91. doi: 10.1007/s42247-019-00046-4

56. Qian Z, Sharma D, Jia W, Radke D, Kamp T, Zhao F. Engineering stem cell cardiac patch with microvascular features representative of native myocardium. Theranostics. (2019) 9:2143-57. doi: 10.7150/thno.29552

57. Kitsara M, Agbulut O, Kontziampasis D, Chen Y, Menasche P. Fibers for hearts: a critical review on electrospinning for cardiac tissue engineering. Acta Biomater. (2017) 48:20-40. doi: 10.1016/j.actbio.2016.11.014

58. Sax H, Bloemberg G, Hasse B, Sommerstein R, Kohler P, Achermann Y, et al. Prolonged outbreak of mycobacterium chimaera infection after open-chest heart surgery. Clin Infect Dis. (2015) 61:67-75. doi: 10.1093/cid/civ198

59. Wu J, Hong Y. Enhancing cell infiltration of electrospun fibrous scaffolds in tissue regeneration. Bioact Mater. (2016) 1:56-64. doi: 10.1016/j.bioactmat.2016.07.001

60. Khorshidi S, Solouk A, Mirzadeh H, Mazinani S, Lagaron JM, Sharifi S, et al. A review of key challenges of electrospun scaffolds for tissue-engineering applications. J Tissue Eng Regen Med. (2016) 10:71538. doi: 10.1002/term.1978

61. Ding H, Cheng Y, Niu X, Hu Y. Application of electrospun nanofibers in bone, cartilage and osteochondral tissue engineering. J Biomater Sci Polym Ed. (2021) 32:536-61. doi: 10.1080/09205063.2020.1849922

62. Kharaziha M, Nikkhah M, Shin SR, Annabi N, Masoumi N, Gaharwar AK, et al. PGS:Gelatin nanofibrous scaffolds with tunable mechanical and structural properties for engineering cardiac tissues. Biomaterials. (2013) 34:6355-66. doi: 10.1016/j.biomaterials.2013.04.045
63. Pomeroy JE, Helfer A, Bursac N. Biomaterializing the promise of cardiac tissue engineering. Biotechnol Adv. (2020)42:107353. doi: 10.1016/j.biotechadv.2019.02.009

64. Pan Y, Zhou X, Wei Y, Zhang Q, Wang T, Zhu M, et al. Small-diameter hybrid vascular grafts composed of polycaprolactone and polydioxanone fibers. Sci Rep. (2017) 7:3615. doi: 10.1038/s41598-017-03851-1

65. Bergmeister H, Seyidova N, Schreiber C, Strobl M, Grasl C, Walter I, et al. Biodegradable, thermoplastic polyurethane grafts for small diameter vascular replacements. Acta Biomater. (2015) 11:104-13. doi: 10.1016/j.actbio.2014.09.003

66. Li J, Celiz AD, Yang J, Yang Q, Wamala I, Whyte W, et al. Tough adhesives for diverse wet surfaces. Science. (2017) 357:378-81. doi: 10.1126/science.aah6362

67. Sridharan D, Palaniappan A, Blackstone BN, Powell HM, Khan M Electrospun aligned coaxial nanofibrous scaffold for cardiac repair. Methods Mol. Biol. (2021) 2193:129-40. doi: 10.1007/978-1-0716-0845-6_13

68. Castilho M, Feyen D, Flandes-Iparraguirre M, Hochleitner G Groll J, Doevendans PAF, et al. Melt electrospinning writing of poly-hydroxymethylglycolide-co-epsilon-caprolactone-based scaffolds for cardiac tissue engineering. Adv Healthc Mater. (2017) 6:18. doi: 10.1002/adhm.201700311

69. Zhao YT, Zhang J, Gao Y, Liu XF, Liu JJ, Wang XX, et al. Self-powered portable melt electrospinning for in situ wound dressing. J Nanobiotechnology. (2020) 18:111. doi: 10.1186/s12951-020-00671-w

Conflict of Interest: The authors declare that the research was conducted in the absence of any commercial or financial relationships that could be construed as a potential conflict of interest.

Publisher's Note: All claims expressed in this article are solely those of the authors and do not necessarily represent those of their affiliated organizations, or those of the publisher, the editors and the reviewers. Any product that may be evaluated in this article, or claim that may be made by its manufacturer, is not guaranteed or endorsed by the publisher.

Copyright $\odot 2022$ Huang, Huo, Cheng and Wang. This is an open-access article distributed under the terms of the Creative Commons Attribution License (CC BY). The use, distribution or reproduction in other forums is permitted, provided the original author(s) and the copyright owner(s) are credited and that the original publication in this journal is cited, in accordance with accepted academic practice. No use, distribution or reproduction is permitted which does not comply with these terms. 